Revista Brasileira de Agricultura Irrigada v.8, no. 6, p.538 - 547, 2014

ISSN 1982-7679 (On-line)

Fortaleza, CE, INOVAGRI - http://www.inovagri.org.br

DOI: $10.7127 /$ rbai.v8n600265

Protocolo 265.14 - 23/09/2014 Aprovado em 08/11/2014

\title{
COMPORTAMENTO DE GOTEJADORES SUBMETIDOS APLICAÇÃO DE FERRO SOLÚVEL, SÓLIDOS EM SUSPENSÃO E FITOPLÂNCTYON
}

\author{
Lilian Cristina Castro de Carvalho ${ }^{1,}$ Rubens Duarte Coelho ${ }^{2}$, Marconi Batista Teixeira ${ }^{3}$, \\ Fernando Nobre Cunha ${ }^{4}$, Nelmício Furtado da Silva ${ }^{5}$
}

\begin{abstract}
RESUMO
Esta pesquisa foi desenvolvida visando quantificar possíveis distúrbios de vazão em emissores gotejadores submetidos à aplicação de ferro solúvel, sólidos em suspensão (partículas de solo). O experimento foi realizado em um período de 12 meses utilizandose 16 modelos de tubos gotejadores novos e 26 modelos de tubos gotejadores em uso, com suas respectivas linhas gotejadoras montadas em uma bancada de ensaios em estrutura metálica localizada no Laboratório de Irrigação, da Escola Superior de Agricultura "Luiz de Queiroz" - ESALQ/USP. No experimento avaliou-se a susceptibilidade de diferentes tubos gotejadores ao entupimento por aplicação de ferro solúvel, carga orgânica (fitoplâncton/algas) e sólidos em suspensão. A arquitetura interna dos emissores avaliados, foi o fator determinante na caracterização do processo de entupimento. Desta forma, adequações podem minimizar tanto a obstrução causada pelo ferro solúvel como os efeitos ocasionados por ela.
\end{abstract}

Palavras-Chave: irrigação localizada, modelos de emissores, vazão, carga orgânica, entupimento.

\section{BEHAVIOR DRIPPERS SUBMITTED APPLICATION OF IRON SOLUBLE SOLID MATTER AND PHYTOPLANKTON}

\footnotetext{
ABSTRACT

This research project was developed to quantify possible disturbances of flow rate in drip emitters subject to the application of soluble iron, suspended solids (soil particles)

${ }^{1}$ Professor do Instituto Federal do Ceará, IFCE. Av. Dr. Guarani, 317, Derby Clube, 62042-030, Sobral, CE. email: liliancarv@ifce.edu.br.

${ }^{2}$ Eng. Agrônomo, Prof. Livre Docente, DER - Departamento de Engenharia Rural, Escola Superior de Agricultura Luiz de Queiroz, Universidade de São Paulo, Piracicaba, SP, C.P.: 9, CEP: 13418-900, fone (0xx19) 3447-8551, email: rdcoelho@esalq.usp.br

3 Eng. Agrônomo, Prof. Dr. Instituto Federal Goiano - IFGoiano - Rio Verde, GO, email: marconibt@gmail.com

${ }^{4}$ Eng. Agrônomo, Doutorando em Ciências Agrárias - Agronomia, IFGoiano - Câmpus Rio Verde, Rio Verde, GO, email: fernandonobrecunha@ hotmail.com

${ }^{5}$ Eng. Agrônomo, Doutorando em Ciências Agrárias - Agronomia, IFGoiano - Câmpus Rio Verde, Rio Verde, GO, email: nelmiciofurtado@gmail.com
} 
in water containing organic material (phytoplankton / algae). The experiments were carried during 12 months period, using 26 models of used drip tubes. The tests were conducted on a bench test located at the Irrigation and Drainage Laboratory of the University of Sao Paulo (ESALQ / USP). Experiment it was assessed the susceptibility of different drip tube for clogging by the application of soluble iron, organic load (phytoplankton / algae) and suspended solids (soil particles). The internal architecture of the emitters evaluated was the determinant in characterizing the process clogging thus adaptations both in the architecture can minimize the obstruction caused by the dissolved iron as the effects caused by it.

Keywords: localized irrigation, emitter models, flow, organic load, clogging.

\section{INTRODUÇÃO}

Nos solos o ferro pode ser encontrado na forma de hematita $\left(\mathrm{Fe}_{2} \mathrm{O}_{3}\right)$, sesquióxido de férrico $\left(\mathrm{Fe}_{2} \mathrm{O}_{3} \cdot 3 \mathrm{H}_{2} \mathrm{O}\right)$ ou siderita $\left(\mathrm{FeCO}_{3}\right)$. Segundo Vanzela (2004), o processo de erosão dos solos formados a base de sesquióxidos de ferro faz com que haja um aumento da concentração de ferro tanto solúvel quanto em suspensão nas águas.

A irrigação localizada, por utilizar emissores com orifícios de passagem de água muito pequenos, está sujeita a alterações nas vazões nos pontos de missão devido ao efeito das obstruções, ocasionando perda da uniformidade de irrigação (BUSATO; SOARES, 2010).

Para Cunha et al. (2013) em um sistema de irrigação por gotejamento, a uniformidade de aplicação de água está relacionada a fatores hidráulicos e à qualidade dos gotejadores, além da qualidade da água e uso da fertirrigação com sais que podem ocasionar o entupimento dos emissores, contribuindo também para a desuniformidade de aplicação.

Nos dias atuais existem inúmeros gotejadores sendo comercializados, onde cada tipo de emissor possui uma sensibilidade própria ao entupimento, contudo, segundo Ravina et al. (1992), todos os gotejadores são vulneráveis a obstrução pelo crescimento biológico, uma vez que, geralmente possuem passagens estreitas e aberturas pequenas, que variam de 0,5 a $1,5 \mathrm{~mm}$.

Normalmente no tratamento químico, adotam-se medidas cujo objetivo é evitar que as obstruções apareçam rapidamente, o que se define como tratamento preventivo. Por outro lado, existem recomendações de tratamento químico, para que as obstruções já existentes sejam destruídas, esse tipo de tratamento chama-se tratamento de limpeza ou de recuperação. Para o tratamento de recuperação dos emissores existem produtos que removem a mucilagem aderida às paredes das tubulações e gotejadores deixando, assim, a passagem de água novamente livre (VIEIRA et al., 2004).

Objetivo com este experimento foi o de avaliar a susceptibilidade de diferentes tubos gotejadores ao entupimento por ferro solúvel na água de irrigação (óxido de ferro, sulfato ferroso e hidróxido de ferro), carga orgânica (fitoplâncton/algas) e sólidos suspensos (partículas de solo).

\section{MATERIAL E MÉTODOS}

A presente pesquisa foi conduzida no Laboratório de Irrigação da Escola Superior de Agricultura "Luiz de Queiroz" - ESALQ/USP, localizada no município de Piracicaba - SP, 
cujo clima é classificado como Cwa subtropical úmido, segundo classificação climática de Köppen, temperatura média máxima superior a $22^{\circ} \mathrm{C}$ e média mínima de $18^{\circ} \mathrm{C}$, ocorrendo chuvas de verão e secas de inverno.

$\mathrm{O}$ experimento foi desenvolvido em uma bancada de ensaios, construída em estrutura metálica composta por três andares, com $11 \mathrm{~m}$ de comprimento, $4 \mathrm{~m}$ de largura e $5,8 \mathrm{~m}$ de altura, sendo cada andar da bancada independente dos demais.

Os andares foram divididos em duas partes, sendo cada uma composta por diferentes níveis para a inserção das linhas gotejadoras que foram unidas no início e no final da bancada por registros e conexões de PVC. Para a condução da água e montagem das linhas de gotejadores do ensaio utilizou-se um registro de 2' na linha principal e um registro de $3 / 4$ ' na entrada de cada nível. $\mathrm{Na}$ entrada de cada módulo da bancada, foi instalada uma tomada de pressão, permitindo o ajuste da pressão a cada medição de vazão, e se necessário, ajustada àquela preestabelecida. Para a medição e monitoramento da pressão de serviço, foi utilizado um manômetro com faixa de leitura de $0-700 \mathrm{kPa}$, calibrado previamente por um manômetro de peso morto.

O sistema de pressurização utilizado no experimento foi composto por um conjunto de motobomba centrífuga da marca KSB, modelo KSB Hydrobloc C 750, cuja operação de funcionamento foi realizada manualmente, obedecendo rigorosamente os horários de início e fim de cada aplicação. Para evitar a entrada de partículas em suspensão no sistema, foi utilizado um filtro de disco de 120 mesh/Amiad, com capacidade para $15 \mathrm{~m}^{3} \mathrm{~h}^{-1}$ de vazão, cuja limpeza era feita a cada 12 horas de funcionamento.

No preparo e armazenamento das soluções utilizaram-se caixas de amianto, com capacidade para $1.000 \mathrm{~L}$, que foram conectadas ao conjunto motobomba por meio de uma sucção de 0,06 m de diâmetro, através de um adaptador de caixa d'água e o bombeamento de cada solução foi controlado por um registro de esfera de $0,06 \mathrm{~m}$, instalado na extremidade da sucção dentro da caixa, permitindo o bombeamento da solução.

O sistema de aplicação da solução foi adaptado de tal forma que permitia um processo de recirculação da mesma, onde a solução gotejada era recolhida por dois conjuntos de telhas de aço zincado (forradas com filme plástico), com uma inclinação de $3 \%$, aonde conduzia a solução para uma calha de zinco revestida com fibra de vidro, localizada no centro do modulo, que retornava a solução para a caixa da respectiva captação, através de um conjunto de tubos PVC de 100 $\mathrm{mm}$.

Ao final da aplicação, os registros eram fechados com o sistema ainda em funcionamento, para evitar o retorno da solução ao reservatório, garantindo assim que a solução permanecesse em contato com toda a superfície interna da linha gotejadora. Para evitar uma perda acentuada da solução ao longo da semana, foram colocadas cortinas de plásticos nas laterais da bancada de ensaio. Após cada ensaio de vazão, o sistema permanecia desligado por um dia, com o objetivo de se fazer limpeza, preparo da nova solução, reparos e manutenção do sistema.

$\mathrm{O}$ experimento foi realizado no módulo 3 da bancada de ensaio, no setor 6 , onde 
realizou-se o tratamento, com duração de 648 horas.

O setor 6, onde foi realizado o experimento, era composto por 26 modelos diferentes de tubos gotejadores, onde destes 9 eram convencionais $(1,2,3,4,5,6,7,8$ e 9) e 17 autocompensantes $(10,11,12,13,14,15$, $16,17,18,19,20,21,22,23,24,25$ e 26$)$.

No tratamento foi aplicado $20,0 \mathrm{mg} \mathrm{L}^{-1}$ de ferro solúvel $\left(\mathrm{Fe}^{+2}\right)$, tendo o hidróxido de ferro como fonte do mesmo, associado a 409 mg $\mathrm{L}^{-1}$ de sólidos suspensos (solo) e a carga orgânica (fitoplânctons) proveniente da água LAG (água do lago) (Tabela 1).

Tabela 1. Análise da água do lago paisagístico pertencente ao departamento de ciências exatas da ESALQ/USP, utilizada na preparação das soluções aplicada no tratamento.

\begin{tabular}{|c|c|c|}
\hline Parâmetro & Unidade & Resultado \\
\hline Alcalinidade $\left(2 \mathrm{CO}_{3}{ }^{2-}+\mathrm{HCO}_{3}{ }^{-}\right)$ & $m g L^{1}$ & 88,4 \\
\hline Cloreto $\left(\mathrm{Cl}^{-}\right)$ & $\mathrm{mg} \mathrm{L}^{1}$ & 19,0 \\
\hline Nitrato $\left(\mathrm{N}-\mathrm{NO}_{3}\right)$ & $\mathrm{mg} \mathrm{L}^{1}$ & 0,6 \\
\hline Sulfato $\left(\mathrm{SO}_{4}{ }^{2-}\right)$ & $\mathrm{mg} \mathrm{L}^{1}$ & 12,1 \\
\hline Fósforo (P) & $\mathrm{mg} \mathrm{L}^{1}$ & 0,14 \\
\hline Nitrogênio Amoniacal $\left(\mathrm{N}-\mathrm{NH}_{3}\right)$ & $\mathrm{mg} \mathrm{L}^{1}$ & 1,1 \\
\hline Sódio $\left(\mathrm{Na}^{+}\right)$ & $\mathrm{mg} \mathrm{L}^{1}$ & 24,0 \\
\hline Potássio $\left(\mathrm{K}^{+}\right)$ & $\mathrm{mg} \mathrm{L}^{1}$ & 6,3 \\
\hline Cálcio $\left(\mathrm{Ca}^{2+}\right)$ & $\mathrm{mg} \mathrm{L}^{1}$ & 17,5 \\
\hline Magnésio $\left(\mathrm{Mg}^{2+}\right)$ & $\mathrm{mg} \mathrm{L}^{1}$ & 3,7 \\
\hline Ferro $(\mathrm{Fe})$ & $\mathrm{mg} \mathrm{L}^{1}$ & 0,75 \\
\hline Cobre $(\mathrm{Cu})$ & $\mathrm{mg} \mathrm{L}^{1}$ & 0 \\
\hline Manganês (Mn) & $\mathrm{mg} \mathrm{L}^{1}$ & 0,04 \\
\hline Zinco (Zn) & $\mathrm{mg} \mathrm{L}^{1}$ & 0,17 \\
\hline Cor Aparente & $\mathrm{mg} \mathrm{L}^{1}$ & 230 \\
\hline Turbidez & $\mathrm{mg} \mathrm{L}^{1}$ & 48 \\
\hline Sedimentos em suspensão & $\mathrm{PtCo}$ & 25 \\
\hline Condutividade elétrica (CE) & FTU & 0,18 \\
\hline $\mathrm{pH}$ & $\mathrm{mg} \mathrm{L}^{1}$ & 7,4 \\
\hline Gás Carbônico $\left(\mathrm{CO}_{2}\right)$ & $\mathrm{mS} \mathrm{cm} \mathrm{cm}^{-1}$ & 5,3 \\
\hline Acidez $\left(\mathrm{CaCO}_{3}\right)$ & --- & 33 \\
\hline Dureza Total $*\left(\mathrm{CaCO}_{3}\right)$ & $\mathrm{mg} \mathrm{L}^{1}$ & 58,7 \\
\hline Coliformes totais/100Ml & $\mathrm{mg} \mathrm{L}^{1}$ & $1,3 \times 10^{3}$ \\
\hline Coliformes termotolerantes $/ 100 \mathrm{~mL}$ & $\mathrm{mg} \mathrm{L}^{1}$ & $9,2 \times 10^{2}$ \\
\hline
\end{tabular}

*Dureza Total calculado com base no equivalente de Carbonato de cálcio $\left(\mathrm{CaCO}_{3}\right)$ segundo Franson (1995): 2,497 [Ca, mg L$\left.{ }^{-1}\right]+4,118\left[\mathrm{Mg}, \mathrm{mg} \mathrm{L}^{-1}\right]$
O tratamento realizado no experimento pode ser resumido da seguinte forma: tratamento (linhas gotejadoras do setor 6): 20,0 $\mathrm{mg} \mathrm{L}^{-1}$ de $\mathrm{Fe}^{+2}$ (hidróxido de ferro) + sólidos suspensos (solo - $409 \mathrm{mg} \mathrm{L}^{-1}$ ) + carga orgânica (água LAG).

As características físicas do solo utilizado no tratamento encontram-se na Tabela 2.

Tabela 2. Características físicas do solo da área experimental.

\begin{tabular}{ccccccc}
\hline \multicolumn{2}{c}{ Granulometria $(\%)$} & & $\begin{array}{c}\text { Classe } \\
\text { Textural }\end{array}$ & \multicolumn{2}{c}{ Densidade $\left(\mathrm{g} \cdot \mathrm{cm}^{-3}\right)$} \\
\cline { 1 - 1 } \cline { 5 - 6 } Argila & silte & areia & & argilosa & global & partículas \\
\cline { 1 - 3 } & & & & & 1,45 & 2,79 \\
\hline
\end{tabular}

Durante o ensaio foram mantidos os espaçamentos originais das linhas gotejadoras, com o objetivo de evitar diferenças relacionadas à influência de emendas e da proximidade dos emissores, reduzindo os erros e mantendo, assim, as mesmas condições das linhas utilizadas pelos irrigantes. Desta forma o número de gotejadores presentes na linha dependeu do espaçamento fornecido pelo fabricante, porém foi assegurado um número mínimo de 10 emissores para cada modelo analisado.

A Tabela 3 apresenta os emissores com suas características técnicas e a vazão mais comercializada pelos irrigantes. Em função dos emissores ensaiados serem produtos comerciais e os ensaios a que foram submetidos não serem normatizados, os dados e análises realizados em todos os ensaios foram codificados para evitar qualquer tipo de especulação comercial dos resultados apresentados. A codificação utilizada na representação dos modelos de emissores, não tem nenhuma relação com os nomes 
comerciais dos produtos e nem tampouco com a sequência de emissores apresentados na Tabela 3.

Tabela 3. Características técnicas: fluxo, vazão, diâmetro nominal $(\varnothing \quad \mathrm{N}) \quad \mathrm{e}$ espaçamento entre gotejadores dos modelos utilizados no experimento.

\begin{tabular}{|c|c|c|c|c|c|}
\hline Fabricante & Modelo & Fluxo & $\begin{array}{l}\text { Vazão } \\
\left(\mathrm{L} \mathrm{h}^{-1}\right)\end{array}$ & $\begin{array}{c}\varnothing \mathrm{N} \\
(\mathrm{mm})\end{array}$ & $\begin{array}{c}\text { Espaçamento } \\
\text { entre } \\
\text { gotejadores } \\
(\mathrm{m})\end{array}$ \\
\hline \multirow{4}{*}{ Naandan } & $\begin{array}{l}\text { Naan tif } \\
\text { PC }\end{array}$ & $\mathrm{AC}$ & 1,6 & 16 & 0,50 \\
\hline & Naan Paz & $\mathrm{NC}$ & 2,0 & 16 & 0,75 \\
\hline & Naan PC & $\mathrm{AC}$ & 2,1 & 16 & 0,80 \\
\hline & Naan PC & $\mathrm{AC}$ & 3,8 & 16 & 0,90 \\
\hline \multirow{6}{*}{ Netafin } & Drip Net & $\mathrm{AC}$ & 1,6 & 16 & 0,75 \\
\hline & Uniran & $\mathrm{AC}$ & 1,6 & 16 & 0,33 \\
\hline & Ram & $\mathrm{AC}$ & 2,3 & 16 & 0,50 \\
\hline & Ram & $\mathrm{AC}$ & 2,3 & 17 & 0,50 \\
\hline & Tiran & $\mathrm{NC}$ & 2,05 & 16 & 0,75 \\
\hline & $\begin{array}{c}\text { Super } \\
\text { Typhoon }\end{array}$ & $\mathrm{NC}$ & 2,0 & 16 & 0,60 \\
\hline \multirow{6}{*}{ Plastro } & Hydrogol & $\mathrm{NC}$ & 3,0 & 17 & 0,40 \\
\hline & Hydro Pc & $\mathrm{AC}$ & 2,0 & 17 & 0,80 \\
\hline & Hydro Pc & $\mathrm{AC}$ & 2,2 & 17 & 0,80 \\
\hline & Hydro Pc & $\mathrm{AC}$ & 2,2 & $16 / 25$ & 0,75 \\
\hline & $\begin{array}{c}\text { Hydro Pc } \\
\text { Nd }\end{array}$ & $\mathrm{AC}$ & 2,35 & $16 / 40$ & 0,80 \\
\hline & $\begin{array}{c}\text { Hydro } \\
\text { Drip }\end{array}$ & $\mathrm{AC}$ & 2,0 & 16 & 0,80 \\
\hline \multirow[b]{2}{*}{ Amanco } & $\begin{array}{l}\text { Carbo } \\
\text { Drip }\end{array}$ & $\mathrm{AC}$ & 2,0 & 17 & 0,80 \\
\hline & $\begin{array}{l}\text { Carbo } \\
\text { Drip } \\
\text { Cd/Ac }\end{array}$ & $\mathrm{NC}$ & 2,2 & 16 & 0,50 \\
\hline \multirow{4}{*}{ Irrimon } & $\begin{array}{l}\text { Twin } \\
\text { Plus }\end{array}$ & $\mathrm{AC}$ & 1,8 & 17,5 & 1,00 \\
\hline & Vip Line & $\mathrm{AC}$ & 3,6 & 16 & 1,00 \\
\hline & $\begin{array}{l}\text { Irridrip } \\
\text { Plus }\end{array}$ & $\mathrm{AC}$ & 2,5 & 16 & 1,00 \\
\hline & Irriloc & $\mathrm{NC}$ & 1,1 & 16,4 & 0,40 \\
\hline Azud & Azudline & $\mathrm{NC}$ & 1,4 & 17 & 0,50 \\
\hline Toro Ag & Drip In & $\mathrm{AC}$ & 2,5 & 17 & 0,75 \\
\hline Petroísa & $\begin{array}{c}\text { Petroísa } \\
\text { G1 }\end{array}$ & $\mathrm{NC}$ & 1,5 & 16 & 0,30 \\
\hline Queen Gil & $\begin{array}{c}\text { Queen } \\
\text { Gil }\end{array}$ & $\mathrm{NC}$ & 4,0 & 16,5 & 0,10 \\
\hline
\end{tabular}

Fonte: Catálogo dos fabricantes
Depois de tabulados os pesos, procederam-se os cálculos da vazão, vazão relativa e do coeficiente de variação de vazão, através das Equações de 1 a 3.

$$
q=\frac{P}{1000 t d} 60
$$

em que:

$\mathrm{q}$ - vazão do gotejador, $\mathrm{L} \mathrm{h}^{-1}$;

$\mathrm{P}$ - peso da água coletada, $\mathrm{g}$;

$\mathrm{t}$ - tempo de coleta, min e

$d$ - densidade da água utilizada no ensaio, $\mathrm{g}$

$\mathrm{L}^{-1}$ (o valor médio utilizado para conversão da água para $25^{\circ} \mathrm{C}$, foi de 0,997 ).

$$
Q_{r}=\frac{Q_{x, y}}{Q_{i}}
$$

em que:

$\mathrm{Q}_{\mathrm{r}}$ - vazão relativa, \%;

$\mathrm{Q}_{\mathrm{x}, \mathrm{y}}$ - vazão de um emissor $\mathrm{x}$ num dia y de irrigação, $\mathrm{L} \mathrm{h}^{-1} \mathrm{e}$

$\mathrm{Q}_{\mathrm{i}}$ - vazão desse emissor no primeiro dia de irrigação, $\mathrm{L} \mathrm{h}^{-1}$.

$$
C V_{q}=\frac{s_{\text {usado }}}{\bar{q}_{\text {usado }}} 100
$$

em que:

$\mathrm{CV}_{q}$ - coeficiente de variação da vazão, \%; $\mathrm{s}_{\text {usado }}$ - desvio padrão da vazão dos gotejadores usados, $\mathrm{L} \mathrm{h}^{-1}$; e

$\bar{q}_{\text {usado }}$ - vazão média do gotejador usado, L $\mathrm{h}^{-1}$.

Para avaliação dos coeficientes de variação utilizou-se a classificação dos valores propostas pela Associação Brasileira de Normas Técnicas - ABNT (1986), logo 
quaisquer comparação entre os modelos e o tempo de irrigação foi baseada na classificação proposta pela ABNT (1986).

\section{RESULTADOS E DISCUSSÃO}

Nas Figuras 1, 2, 3 e 4 encontram-se a vazão relativa dos emissores utilizados no tratamento com $20 \mathrm{mg} \mathrm{L}^{-1}$ de $\mathrm{Fe}^{+2}$ (hidróxido de ferro) + água LAG + sólidos suspensos (400 mg L ${ }^{-1}$ ). De acordo com estas Figuras o melhor desempenho foi alcançado pelos modelos 3, 8 e 22 que praticamente mantiveram seus valores de vazão relativa em $100 \%$ durante todo o funcionamento e o pior foi demonstrado pelos emissores dos modelos 1, 19 e 26 que ao final do ensaio apresentaram reduções de 43,42 e $34 \%$.

O modelo 24, após 360 horas de funcionamento apresentou rompimento do tubo gotejador em diferentes pontos não sendo possível a continuidade da aplicação do tratamento para este emissor, devido, provavelmente a este emissor possuir uma parede de tubo muito fina, tornando-o mais suscetível ao rompimento após diferentes ensaios.

$\mathrm{Na}$ Figura 1 e 2, pode-se observar que, com exceção dos modelos 1 e 24 , houve uma leve tendência de redução de vazão nos demais modelos de emissores, não ultrapassando a 20\%. Esta baixa redução da vazão pode estar associada ao tamanho das partículas de solo utilizado na aplicação dos tratamentos como observado por Coelho et al. (2014) onde associaram a não suficiência para ocasionar bruscas reduções de vazão no tubo gotejadores ao tamanho das partículas.

Analisando a Figura 3, observa-se que após 72 horas de funcionamento houve um aumento de 10 e $34 \%$ nos valores de vazão relativa dos modelos 15 e 16, respectivamente, fato, este bem comum na fase inicial do entupimento com aumento de vazão em emissores autocompensantes, devido a um desequilíbrio na membrana de autocompensação, no entanto no final do experimento houve redução de vazão em $32 \%$ no modelo 15, já o modelo 16 reduziu sua vazão em algumas horas do experimento, porém ao final do mesmo apresentou um aumento de $4 \%$ de vazão. Os modelos 5, 11, 14, 20 e 22 apresentaram, ao final do experimento, uma redução de vazão inferior a $20 \%$.

$\mathrm{Na}$ Figura 4, nota-se que embora os modelos 12, 18, e 23 tenham apresentado elevação de vazão em algum momento do experimento, ao final de 648 horas de funcionamento demonstraram redução de vazão, da ordem de 27,11 e $15 \%$, respectivamente. $\mathrm{O}$ modelo 21 apresentou elevação de vazão ao longo de todo o experimento. De maneira geral estes resultados corroboram com Busato et al. (2012) onde afirmam que o uso de água com elevados teores de ferro total para a irrigação por gotejamento apresenta grande potencial para obstrução de gotejadores.

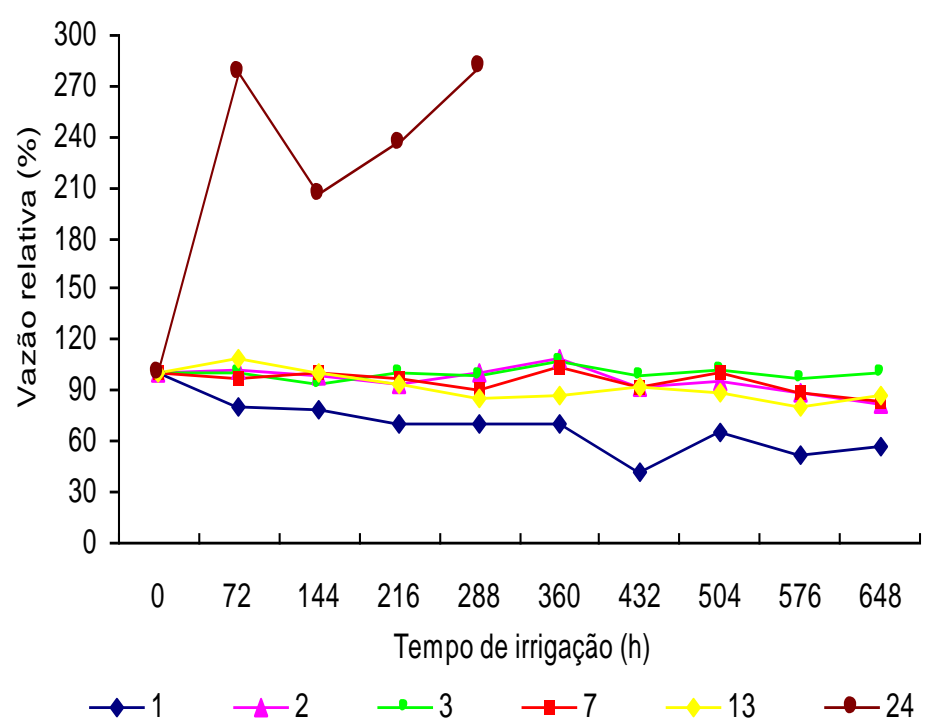

Figura 1. Vazão relativa dos gotejadores 1, 2, 3, 7, 13 e 24 em função do tempo de irrigação. 


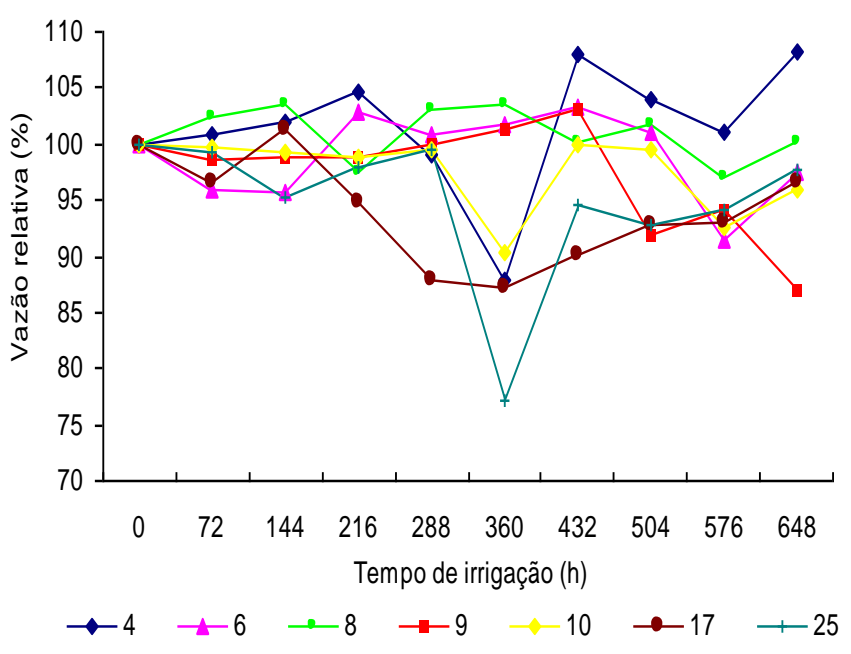

Figura 2. Vazão relativa dos gotejadores $4,6,8$, $9,10,17$ e 25 em função do tempo de irrigação.

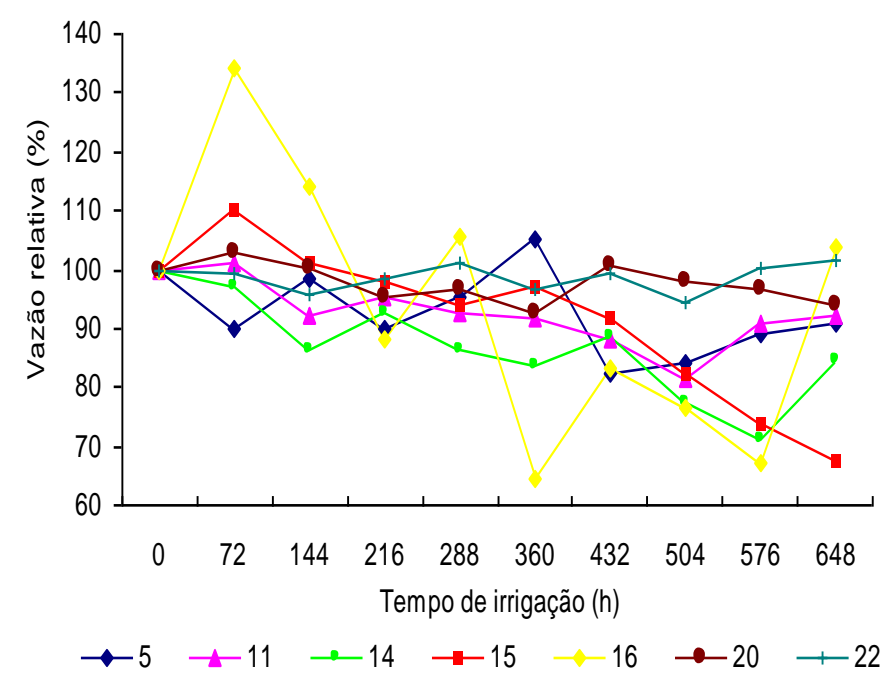

Figura 3. Vazão relativa dos gotejadores 5,11 , $14,15,16,20$ e 22 em função do tempo de irrigação.

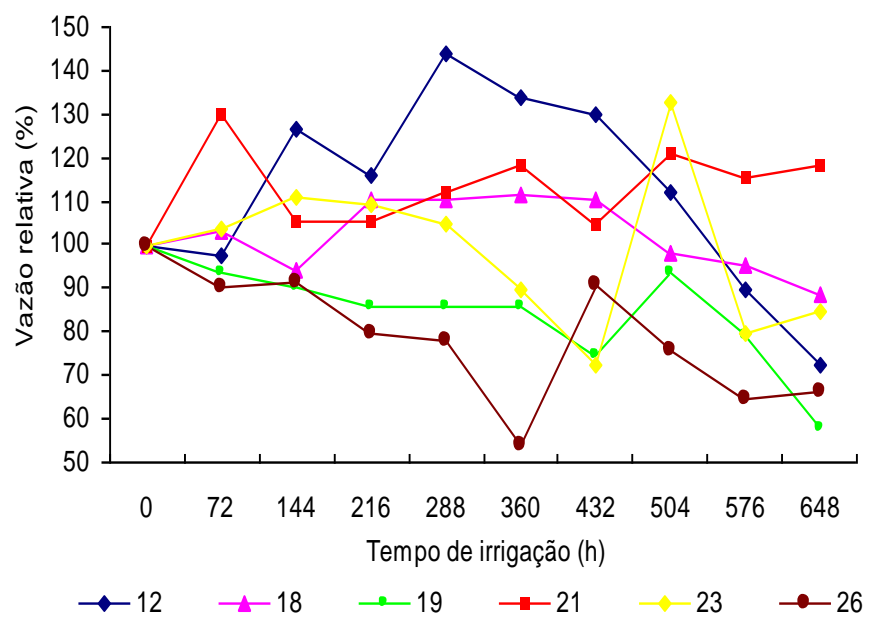

Figura 4. Vazão relativa dos gotejadores 12,18 , 19, 21, 23 e 26 em função do tempo de irrigação.
Nas Figuras 5, 6, 7 e 8 encontram-se os valores de coeficiente de variação de vazão dos modelos de emissores. Analisando estas Figuras, observa-se que o coeficiente de variação de vazão inicial (0 hora), dos emissores usados, variou entre 2,36 (modelo 10) e $153,4 \%$ (modelo 12). Os emissores dos modelos 2 a 11 e os dos modelos 14, 18, 20, 25 mantiveram seus valores de coeficiente de variação inicial dentro dos limites considerados bons de acordo com a classificação da ABNT (1986), indicando que estes modelos, mesmo sendo usados, possuem boa qualidade. Ainda para o coeficiente de variação de vazão inicial, os modelos 15 e 17 são considerados médios e os modelos 1, 12, 13, 16, 19, 21, 22, 23, 24 e 26 inaceitáveis.

O maior valor de coeficiente de variação de vazão foi apresentado pelo modelo 12, que chegou a 193,9\% ao final do experimento.

Conforme a Figura 5, pode-se observar que o modelo 3 manteve-se aceitável para irrigação em todo o período ensaiado e de acordo com a Figura 1, também não houve variação de vazão neste emissor. Os modelos $1,2,7$ e 13 apresentaram valores finais de coeficiente de variação da ordem de 50,74; 36,$17 ; 36,04$ e $36,92 \%$, respectivamente. Conforme já fora mencionado, o modelo 24 após 360 horas de funcionamento apresentou rompimento do tubo gotejador em diferentes pontos não sendo possível a continuidade da aplicação do tratamento.

Comparando os valores de coeficiente de variação de vazão inicial (0 hora) e a 648 h de funcionamento (Figura 6), nota-se que, excetuando-se o modelo 9 , os demais modelos $(4,6,8,10,17$ e 25$)$ mantiveram-se inferiores 
a $10 \%$, portanto dentro da faixa considerada como bons emissores.

Conforme Figura 7, pode-se observar que os modelos 16 e 22 apresentaram valores de coeficiente de variação de vazão em níveis inaceitáveis por todo o experimento e os modelos 14 e 15 tornaram-se inaceitáveis a partir de 288 e 72 horas de funcionamento, respectivamente.

Os modelos 12, 21, 23 e 26, observados na Figura 8, apresentaram valores superiores a $30 \%$ ao longo de todo o experimento, sendo o pior desempenho alcançado pelo modelo 12 , cujo coeficiente de variação manteve-se superior a $120 \%$ durante todo o ensaio. $\mathrm{O}$ modelo 18 somente apresentou-se inadequado após 576 horas de funcionamento e o modelo 19 apresentou coeficiente de variação de vazão inicial $(0 \mathrm{~h})$ superior aos valores aceitáveis, porém a partir de $216 \mathrm{~h}$ demonstrou valores inferiores a $10 \%$ elevando novamente para níveis inaceitáveis $(68,8 \%)$ ao final do experimento.

Comparando o coeficiente de variação de vazão inicial ( 0 hora), dos emissores usados, utilizados nas Figuras 5 a 8 observouse que mesmo depois de vários ensaios e tratamentos de desobstruções os modelos de 4 a 11 mantiveram-se dentro dos limites considerados bons de acordo com a classificação da ABNT (1986), portanto mostrando-se de boa qualidade. E que, os emissores dos modelos 19, 21 e 23 mostraramse inaceitáveis para a irrigação. Segundo Teixeira et al. (2008), para prevenir o entupimento dos emissores, a avaliação sistemática do sistema de irrigação e o monitoramento da qualidade da água são essenciais.

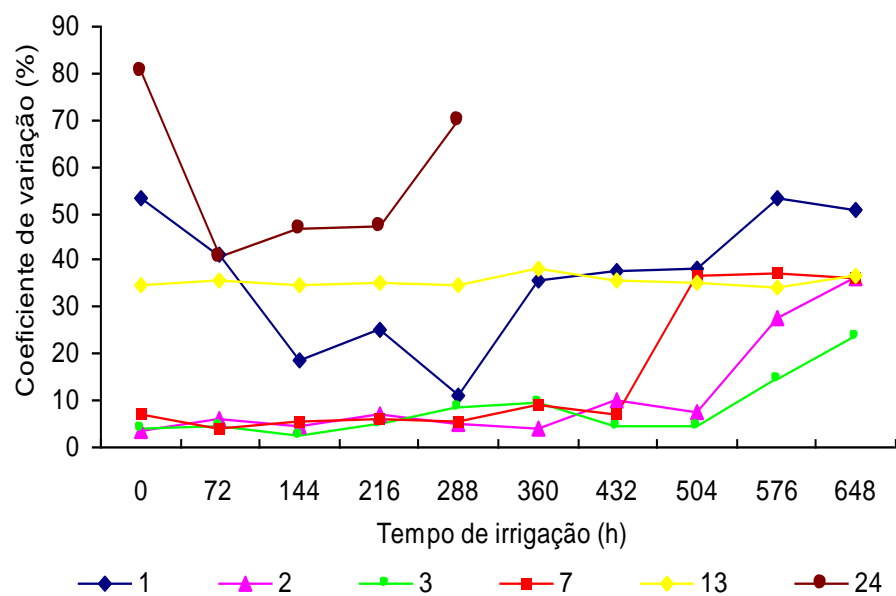

Figura 5. Coeficiente de variação dos gotejadores $1,2,3,7,13$ e 24 em função do tempo de irrigação.

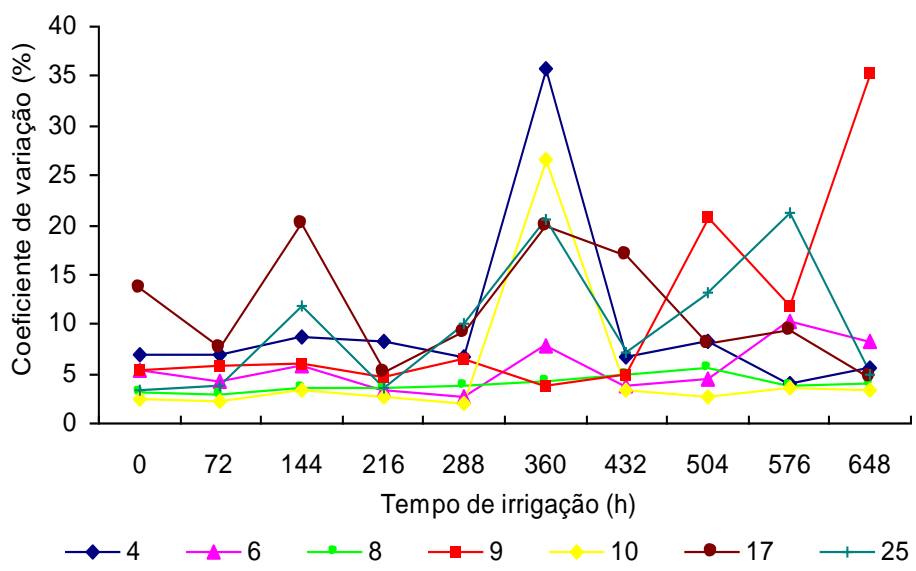

Figura 6. Coeficiente de variação dos gotejadores $4,6,8,9,10,17$ e 25 em função do tempo de irrigação.

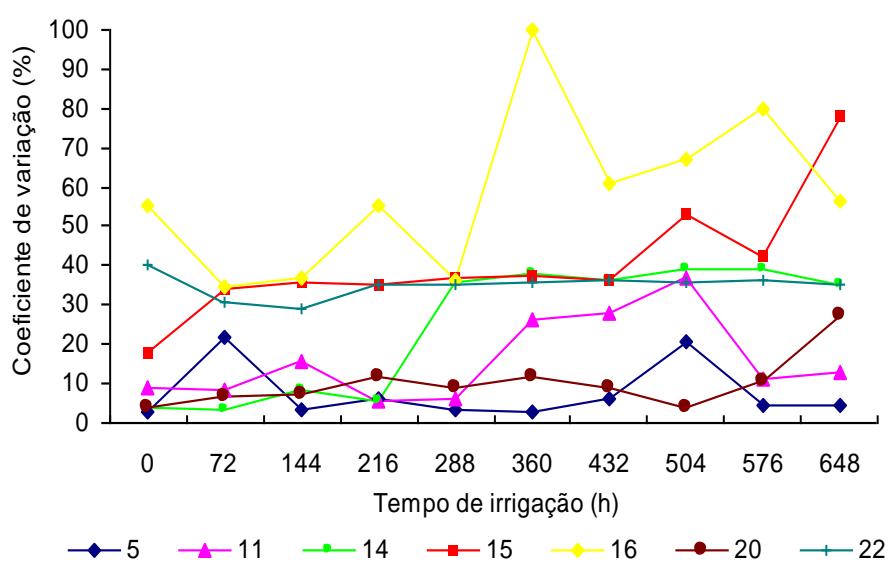

Figura 7. Coeficiente de variação dos gotejadores $5,11,14,15,16,20$ e 22 em função do tempo de irrigação. 


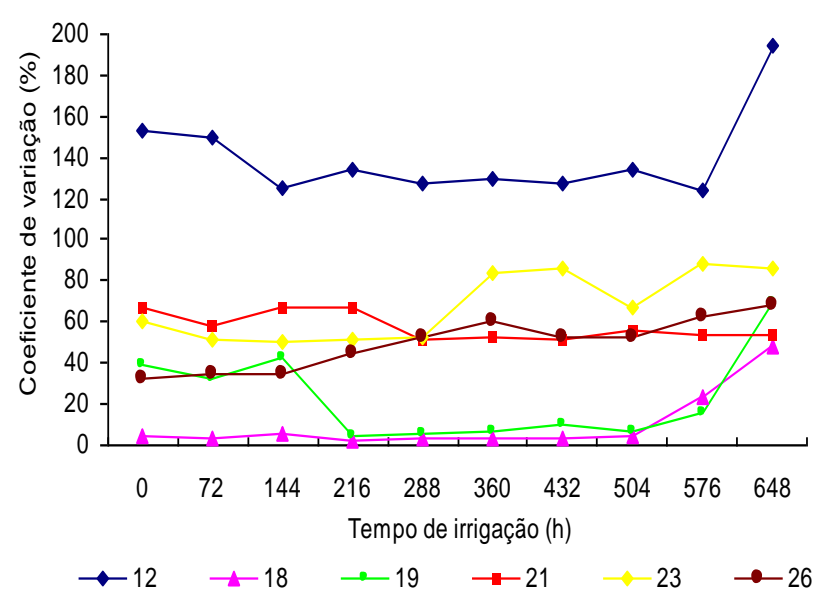

Figura 8. Coeficiente de variação (\%) dos gotejadores 12, 18, 19, 21, 23 e 26 em função do tempo de irrigação.

\section{CONCLUSÕES}

Após 72 horas de funcionamento houve um aumento de 10 e $34 \%$ nos valores de vazão relativa dos modelos 15 e 16, devido a um desequilíbrio na membrana de autocompensação.

Os modelos 12, 21, 23 e 26, apresentaram valores superiores a $30 \%$ ao longo de todo o experimento, sendo o pior desempenho alcançado pelo modelo 12 , cujo coeficiente de variação manteve-se superior a $120 \%$ durante todo o ensaio.

A arquitetura interna dos emissores avaliados foi $o$ fator determinante na caracterização do processo de entupimento, desta forma, adequações na arquitetura podem minimizar tanto a obstrução causada pelo ferro solúvel como os efeitos ocasionados por ela.

\section{REFERÊNCIAS BIBLIOGRÁFICAS}

ASSOCIAÇÃO BRASILEIRA DE NORMAS TÉCNICAS. Emissores para sistemas de irrigação localizada: avaliação das características operacionais; PNBR 12: 02-08021. São Paulo, 1986. 7 p.

BUSATO, C. C. M.; SOARES, A. A.; REIS, E. F., RAMOS, M. M. Influência do entupimento no desempenho de gotejadores aplicando água ferruginosa. Engenharia Ambiental - Espírito Santo do Pinhal, v. 9, n. 2, p. 119-128, abr/ jun. 2012.

BUSATO, C.C.M.; SOARES. A.A. Desempenho de gotejadores, utilizando água de baixa qualidade química e biológica. Bioscience Journal, Uberlândia, v.26, n.5, p.739-746, 2010.

COELHO, R. D.; TEIXEIRA, M. B.; CARVAlHO, L. C. C.; CUNHA, F. C.; SILVA, N. F. Distúrbios de vazão em gotejadores devido o uso de água com presença de ferro. Revista Brasileira de Agricultura Irrigada v.8, no. 3, p. 234 - 246, 2014

CUNHA, F. N.; OLIVEIRA, R. C.; SILVA, N. F.; MOURA, L. M. F.; TEIXEIRA, M. B.; GOMES FILHO, R. R. Variabilidade temporal da uniformidade de distribuição em sistema de gotejamento. Revista Brasileira de Agricultura Irrigada, v.7, n. 4, p. 248 - 257, 2013.

RAVINA, I.; PAZ, E.; SOFER, Z.; MARCU, A.; SCHISCHA, A.; SAGI, G. Control of emitter clogging in drip irrigation with reclaimed wastewater. Irrigation Science, New York, v. 13, p. 129-139, 1992.

TEIXEIRA, M. B.; MELO, R. F. de; COELHO, R. D.; RETTORE NETO, O.; 
RIBEIRO, P. A. de A. Tratamento para desentupimento de gotejadores convencionais. Irriga, Botucatu, v. 13, n. 2, p. 235-248, 2008.

VANZELA, L.S. Qualidade de água para a irrigação na microbacia do Córrego Três Barras no Município de Marinópolis. 2004. 105 p. Dissertação (Mestrado em Sistema de Produção) - Faculdade de Engenharia de Ilha
Solteira. Universidade Estadual Paulista "Júlio de Mesquita Filho”, Ilha Solteira, 2004.

VIEIRA， G.H.S.; MANTOVANI, E.C.; SILVA, J.G.F.; RAMOS, M.M.; SILVA, C.M. Recuperação de gotejadores obstruídos de devido à utiliza utilização de águas ferruginosas. Revista Brasileira de Engenharia Agrícola e Ambiental, Campina, Grande, v. 8, n. 1, p. 1-6, 2004. 